LIVER

\title{
Increased circulating pro-brain natriuretic peptide (proBNP) and brain natriuretic peptide (BNP) in patients with cirrhosis: relation to cardiovascular dysfunction and severity of disease
}

\author{
J H Henriksen, J P Gøłze, S Fuglsang, E Christensen, F Bendtsen, S Møller
}

See end of article for authors' affiliations

\section{Correspondence to:} Professor J H Henriksen, Department of Clinical Physiology, 239, Hvidovre Hospital/University of Copenhagen, DK-2650 Hvidovre, Denmark jens.h.henriksen@hh. hosp.dk

Accepted for publication 25 June 2003

\begin{abstract}
Background and aims: Cardiac dysfunction may be present in patients with cirrhosis. This study was undertaken to relate plasma concentrations of cardiac peptides reflecting early ventricular dysfunction (pro-brain natriuretic peptide (proBNP) and brain natriuretic peptide (BNP)) to markers of severity of liver disease, cardiac dysfunction, and hyperdynamic circulation in patients with cirrhosis.

Patients and methods: Circulating levels of proBNP and BNP were determined in 51 cirrhotic patients during a haemodynamic investigation.

Results: Plasma proBNP and BNP were significantly increased in cirrhotic patients (19 and $12 \mathrm{pmol} / \mathrm{l}$, respectively) compared with age matched controls ( 14 and $6 \mathrm{pmol} / \mathrm{l} ; \mathrm{p}<0.02$ ) and healthy subjects $(<15$ and $<5.3 \mathrm{pmol} / \mathrm{l} ; \mathrm{p}<0.002)$. Circulating proBNP and BNP were closely correlated $(r=0.89, \mathrm{p}<0.001)$, and the concentration ratio proBNP/BNP was similar to that of control subjects $(1.8 v 2.3 ; \mathrm{NS})$. Circulating proBNP and BNP were related to severity of liver disease (Child score, serum albumin, coagulation factors 2,7 , and 10, and hepatic venous pressure gradient) and to markers of cardiac dysfunction (QT interval, heart rate, plasma volume) but not to indicators of the hyperdynamic circulation. Moreover, in multiple regression analysis, proBNP and BNP were also related to arterial carbon dioxide and oxygen tensions. The rate of hepatic disposal of proBNP and BNP was not significantly different in cirrhotic patients and controls.

Conclusion: Elevated circulating levels of proBNP and BNP in patients with cirrhosis most likely reflects increased cardiac ventricular generation of these peptides and thus indicates the presence of cardiac dysfunction, rather than being caused by the hyperdynamic circulatory changes found in these patients.
\end{abstract}

O ur knowledge of cardiovascular pathophysiology, including understanding of the circulatory complications of liver disease, has improved considerably during the last years. The systemic circulation in patients with advanced cirrhosis is hyperdynamic with increased heart rate and cardiac output and decreased systemic vascular resistance with normal or low arterial blood pressure. ${ }^{1-3}$ The use of new investigative modalities has shown several lines of evidence of impaired cardiac contractility and performance in patients with cirrhosis. ${ }^{4-7}$ Moreover, a prolonged $\mathrm{QT}_{\mathrm{C}}$ syndrome and dyssynchronous electrical and mechanical function have been described in patients with cirrhosis. ${ }^{8}{ }^{9}$ This has led to the introduction of a new clinical entity: cirrhotic cardiomyopathy.$^{10-12}$ The term implies a condition with defective myocardial contractility under physical and pharmacological strain. However, the entity has not yet been definitively classified, and the mechanisms behind the cardiac abnormalities are only partly understood..$^{13-17}$

Previous studies have shown increased plasma concentrations of brain natriuretic peptide (BNP) in some patients with cirrhosis. ${ }^{18-20}$ These findings may suggest cardiac dysfunction. Recently, however, the propeptide of brain natriuretic peptide (proBNP) has been suggested as an even better indicator of early cardiac dysfunction. ${ }^{21-24}$ Until now, no study has assessed concentrations of circulating proBNP in patients with cirrhosis. The present study was therefore undertaken to determine concentrations of circulating proBNP and BNP in patients with cirrhosis. Levels of these cardiac peptides were related to markers of severity of disease, cardiac function, and the hyperdynamic circulation in these patients.

\section{MATERIAL AND METHODS Study population}

The study comprised 51 patients ( 16 females, 35 males) with cirrhosis. The diagnosis was biopsy verified in 25 patients. In the remaining patients, the diagnosis was based on established clinical, biochemical, and ultrasonography criteria. Mean age was 50 years (range 33-69). All patients had a history of alcohol abuse (that is, consumption exceeding $50 \mathrm{~g} /$ day for more than five years). All patients had abstained from alcohol for at least one week prior to the study. No withdrawal symptoms were present at the time of the study. According to the modified Child-Turcotte classification, 15 patients were in class A, 23 in class B, and 13 in class C. Twenty one patients had ascites. Twenty eight patients were receiving diuretics and had been put on a sodium restricted diet of $40 \mathrm{mmol}$ sodium per day, but additional cardiovascular medication, including beta blockers, was not prescribed for any of the patients. None of the patients had experienced recent gastrointestinal bleeding or had encephalopathy above grade I. None had signs of heart failure, organic renal disease, diabetes, cancer, or any other major disease. All patients had normal cardiac physical examination, and in those who had a chest $x$ ray performed, signs of cardiomegaly were absent. ECG showed normal configurations apart from sporadic

Abbreviations: BNP, brain natriuretic peptide; proBNP, pro-brain natriuretic peptide; ANP, atrial natriuretic peptide 
Table 1 Clinical and biochemical data of patients with cirrhosis and controls

\begin{tabular}{|c|c|c|}
\hline & Cirrhosis group & Control group \\
\hline Age (y) & $50.5(1.3)$ & $54.1(3.4)$ \\
\hline $\operatorname{Sex}(M / F)$ & $35 / 16$ & $6 / 7$ \\
\hline Body height $(\mathrm{cm})$ & $172(1.3)$ & $167(2.5)$ \\
\hline Body weight (kg) & $70.0(2.3)$ & $61.5(4.8)$ \\
\hline Body mass index $\left(\mathrm{kg} / \mathrm{m}^{2}\right)$ & $23.6(0.7)$ & $22.0(1.6)$ \\
\hline Ascites $(+/-)$ & $21 / 30$ & \\
\hline Diuretics (no/yes) & $23 / 28$ & \\
\hline Serum albumin $(\mu \mathrm{mol} / \mathrm{l} ; 540-800) \dagger$ & $480(12)$ & $527(16)$ \\
\hline Serum alanine aminotransferase (U/I; 10-40) & $78(29)^{*}$ & $21(1.5)$ \\
\hline Serum bilirubin ( $\mu \mathrm{mol} / \mathrm{l} ; 2-17)$ & $40(11)^{*}$ & $7.0(0.7)$ \\
\hline Serum alkaline phosphatase (U/I; 50-275) & $358(28)^{*}$ & $169(25)$ \\
\hline Coagulation factors $2,7,10$ (index; 0.70-1.30) & $0.60(0.04)^{*}$ & $1.04(0.05)$ \\
\hline Galactose elimination capacity (mmol/min; $M>1.70, F>1.40$ ) & $1.59(0.07)$ & - \\
\hline Indocyanine green clearance $(\mathrm{ml} / \mathrm{min} ; 300-700)$ & $247(23)^{*}$ & $469(40)$ \\
\hline Serum $\mathrm{Na}(\mathrm{mmol} / \mathrm{l} ; 136-146)$ & $135(1)$ & $139(1)$ \\
\hline Serum K (mmol/l; 3.5-5.0) & $4.0(0.1)$ & $4.3(0.1)$ \\
\hline Serum creatinine $(\mu \mathrm{mol} / 1 ; 40-110)$ & $79(7)$ & $80(6)$ \\
\hline Haemoglobin (mmol/l; 7.5-10.9) & $7.4(0.2)$ & $7.8(0.3)$ \\
\hline \multicolumn{3}{|l|}{$\begin{array}{l}\text { Values are mean (SEM). } \\
\text { †Reference interval in parentheses. } \\
\text { Significant difference compared with controls: }{ }^{*} \mathrm{p}<0.02 \text {. }\end{array}$} \\
\hline
\end{tabular}

extrasystoles in some patients. Clinical and biochemical characteristics of the patients are summarised in table 1.

The control group comprised 13 patients without liver disease, who were referred for haemodynamic investigation to exclude circulatory disorders, mainly intestinal ischaemia, for which no evidence was found. All controls had normal arterial blood pressure, no signs of major organic disease, and had a normal cardiac physical examination. The clinical and biochemical data are summarised in table 1 .

\section{Catheterisation}

All subjects underwent hepatic vein catheterisation for diagnosis and assessment of portal hypertension and splanchnic haemodynamics. They were studied in the morning after an overnight fast and after at least one hour of resting supine. Catheterisation of the hepatic veins and the right atrium was performed as previously described. ${ }^{25-27}$ In brief, a Swan-Ganz 7F catheter was introduced under local anaesthesia via the femoral route under fluoroscopy. A small indwelling polyethylene catheter was placed in the femoral artery and advanced to the aortic bifurcation using the Seldinger technique. Pressures were measured by a capacitance transducer (Simonsen and Weel, Copenhagen, Denmark) in the wedged and free hepatic vein position, in the right atrium, and in the aorta.

Cardiac output was determined by the indicator dilution technique $\left(150 \mathrm{kBq}{ }^{125} \mathrm{I}\right.$ albumin). ${ }^{25}$ Stroke volume was determined as cardiac output divided by heart rate. Systemic vascular resistance was assessed as 80 (mean arterial pressure-right atrial pressure)/cardiac output. Central circulation time was determined as the time weighted area under the indicator concentration time curve, as previously described. ${ }^{25}$ Central blood volume was measured as cardiac output multiplied by central circulation time. ${ }^{25}$ Plasma volume and blood volume were determined by the indicator dilution technique, as described elsewhere. ${ }^{25} 27$

Hepatic blood flow was determined by the indocyanine green constant infusion technique. ${ }^{28}$ Indocyanine green clearance was determined as the infusion rate divided by arterial plasma concentration. The galactose elimination capacity was determined as described by Tygstrup.

ECG was recorded by a conventional non-computerised electrocardiograph (Siemens Elema, Freiburg, Germany). The QT interval was determined on the ECG $(25-50 \mathrm{~mm} / \mathrm{s})$, as described elsewhere. ${ }^{9}$ QT interval length was taken from the onset of the QRS complex to the end of the T wave (that is, return to the T-P baseline) and was only measured with a stable isoelectric line. In the few cases where $\mathrm{U}$ waves were present, the QT interval was measured to the nadir of the curve between the T and U waves. QT intervals were corrected $\left(\mathrm{QT}_{\mathrm{C}}\right)$ using Bazett's formula, $\mathrm{QT}_{\mathrm{C}}=\mathrm{QT}(\mathrm{RR})^{-1 / 2}$, where RR is the $\mathrm{R}-\mathrm{R}$ interval in seconds. ${ }^{29}$ Prolonged $\mathrm{QT}_{\mathrm{C}}$ interval was defined as $\mathrm{QT}_{\mathrm{c}}>0.440 \mathrm{~s}^{1 / 2}$.

\section{Biochemical analysis}

Arterial oxygen and carbon dioxide tensions and $\mathrm{pH}$ were measured by an ABL-300 blood gas analyser (Radiometer, Copenhagen, Denmark).

\section{Plasma proBNP and BNP analysis}

Plasma proBNP concentrations were determined using a novel processing independent assay recently developed in our laboratory. ${ }^{30}$ This assay quantitates total proBNP products in plasma using a preanalytical enzymatic step. Briefly, plasma is incubated with trypsin to cleave the proBNP forms at a monobasic cleavage site. The enzymatic reaction is then terminated and the released $\mathrm{N}$ terminal fragment (proBNP 121 ) subsequently measured by an $N$ terminal specific proBNP radioimmunoassay. Assay sensitivity is $0.2 \mathrm{pmol} / \mathrm{l}$ (mean zero binding $+3 \mathrm{SD}, \mathrm{n}=10$ ) with an upper reference limit in individuals without cardiac disease of $15 \mathrm{pmol} / \mathrm{l}$ (confidence interval 9-16 pmol/l). The intra-assay coefficient of variation is $12 \%$ at $5 \mathrm{pmol} / \mathrm{l}, 7 \%$ at $75 \mathrm{pmol} / \mathrm{l}$, and $5 \%$ at $130 \mathrm{pmol} / \mathrm{l}$.

For plasma BNP measurements, we used a commercially available assay (Shionogi, Osaka, Japan). ${ }^{31-33}$ This solid phase immunoradiometric assay detects the BNP-32 peptide using two monoclonal antibodies prepared against sterically remote epitopes and does not cross react with atrial or $\mathrm{C}$ type natriuretic peptide. The upper reference limit is $5.3 \mathrm{pmol} / \mathrm{l}$ (defined as mean +1.96 SD) with a detection limit of $0.56 \mathrm{pmol} / \mathrm{l}$. The intra-assay coefficient of variation is $2.7 \%$ at $6.4 \mathrm{pmol} / \mathrm{l}, 2.2 \%$ at $43.9 \mathrm{pmol} / \mathrm{l}$, and $2.0 \%$ at $148.5 \mathrm{pmol} / \mathrm{l}^{31}$

The hepatic extraction ratio of proBNP and BNP was determined as the arterial-hepatic venous concentration difference relative to the arterial concentration. Hepatic clearance was calculated as hepatic plasma flow multiplied by the extraction ratio. Disposal rate was determined as hepatic plasma flow multiplied by the arterial-hepatic venous concentration difference. 


\section{Statistics}

Data are expressed as mean (SEM). One way analysis of variance (ANOVA) with Tukey's post hoc pairwise multiple comparison procedure was used to analyse group data. In cases of non-normality, the Kruskal-Wallis test (with Dunn's pairwise comparison) was applied. Bivariate data were compared by Student's paired/unpaired $t$ tests as appropriate. In cases of non-normality, Wilcoxon/Mann-Whitney tests were applied. Correlations were performed by the Pearson regression analysis or in the case of non-linearity by the Spearman-Rank test. Multiple regression analysis was performed to evaluate the relation between proBNP and BNP on the one hand and pertinent clinical, biochemical, and haemodynamic variables on the other. All variables were initially examined and included stepwise by the forward selection method. The two tailed significance level of the type 1 error was fixed at 0.05 .

\section{RESULTS}

Splanchnic haemodynamics are summarised in table 2. All patients had significantly increased portal venous pressure with a hepatic venous pressure gradient significantly increasing from Child class A to class $\mathrm{C}$ patients.

Systemic haemodynamics are summarised in table 3. Patients with advanced cirrhosis (Child classes B and C) had a hyperdynamic systemic circulation with increased cardiac output, low arterial blood pressure and systemic vascular resistance, increased plasma and blood volumes, and reduced central circulation time. Right atrial pressure was normal in all groups but a substantial amount of patients with cirrhosis (41\%) had an increased QT interval, as reflected by the frequency adjusted $\mathrm{QT}_{\mathrm{C}}$ exceeding $0.440 \mathrm{~s}^{1 / 2}$.

Circulating concentrations of proBNP and BNP were closely correlated in patients with cirrhosis as well as in controls $(r=0.89, \mathrm{p}<0.001$, and $r=0.98, \mathrm{p}<0.001$, respectively) (see fig 1). The ratio plasma proBNP/BNP was similar in patients with cirrhosis and controls ( $1.8 \vee 2.3$; NS) (see table 4).

Circulating concentrations of proBNP as well as BNP in plasma from the artery and cubital vein were significantly increased compared with controls $(p<0.02)$ and age matched healthy subjects $(\mathrm{p}<0.002)$ (tables 4,5 ; fig 2$)$. Plasma proBNP and BNP were significantly higher $(p<0.05)$ in Child class $B$ and $C$ patients compared with class A patients (see fig 2). (Exclusion of outliers in class $A$ and class $C$ from the statistical analyses gave the same result.) When relating proBNP and BNP concentrations to Child score in the univariate analysis, there was a significant direct relation with respect to both proBNP $(r=0.38, \mathrm{p}<0.01)$ and BNP $(r=0.36, \mathrm{p}=0.01)$. ProBNP and BNP concentrations were both borderline significantly related to the hepatic venous pressure gradient $(r=0.27-0.28, \mathrm{p} \leqslant 0.06)$ and inversely related to coagulation factors 2,7 , and $10(r=-0.43$ and $r=-0.43, \mathrm{p}<0.01)$ and serum albumin $(r=-0.32$ and $r=-0.31, \mathrm{p}=0.03)$.

Circulating proBNP was directly related to QT interval $(r=0.36, \mathrm{p}=0.02)$ (fig 3$)$ and to plasma volume $(r=0.27$, $\mathrm{p}=0.05)$. BNP was directly related to QT interval $(r=0.31$, $\mathrm{p}=0.03)$ (fig 3) and to plasma volume $(r=0.36, \mathrm{p}=0.02)$, blood volume $(r=0.29, \mathrm{p}=0.04)$, and stroke volume

Table 2 Splanchnic haemodynamics in patients with cirrhosis

\begin{tabular}{|c|c|c|c|c|c|c|}
\hline & \multicolumn{3}{|c|}{ Cirrhosis (Child group) } & \multirow[b]{2}{*}{ Total cirrhosis $(n=51)$} & \multirow[b]{2}{*}{ Controls $(n=13)$} & \multirow[b]{2}{*}{ ANOVA } \\
\hline & $A(n=15)$ & $B(n=23)$ & $C(n=13)$ & & & \\
\hline Hepatic blood flow (I/min) & $1.38(0.13)$ & $1.36(0.11)$ & $1.28(0.29)$ & $1.35(0.09)$ & $1.09(0.10)$ & NS \\
\hline $\begin{array}{l}\text { Hepatic venous pressure } \\
\text { gradient }(\mathrm{mm} \mathrm{Hg})\end{array}$ & $10.7(1.5)^{a}$ & $18.0(0.8)^{a b}$ & $18.7(2.0)^{a b}$ & $15.9(0.9)^{\mathrm{a}}$ & $2.9(0.3)$ & $\mathrm{p}<0.001$ \\
\hline
\end{tabular}

Values are mean (SEM).

aSignificant difference from controls $(p<0.01)$; ${ }^{b}$ significant difference from Child class $A(p<0.05)$.

Table 3 Systemic haemodynamics in patients with cirrhosis

\begin{tabular}{|c|c|c|c|c|c|c|}
\hline & \multicolumn{3}{|c|}{ Cirrhosis (Child group) } & \multirow{2}{*}{$\begin{array}{l}\text { Total cirrhosis } \\
(n=51)\end{array}$} & \multirow[b]{2}{*}{ Controls $(n=13)$} & \multirow[b]{2}{*}{ ANOVA } \\
\hline & $A(n=15)$ & $B(n=23)$ & $C(n=13)$ & & & \\
\hline \multicolumn{7}{|l|}{ Arterial blood pressure $(\mathrm{mm} \mathrm{Hg})$} \\
\hline Systolic & $143(6)$ & $138(4)$ & $126(7)$ & $136(3)$ & $143(9)$ & \\
\hline Diastolic & $69(3)$ & $65(2)$ & $60(3)$ & $65(2)$ & $67(3)$ & \\
\hline Mean & $94(5)$ & $93(3)$ & $84(5)$ & $91(2)$ & $98(5)$ & \\
\hline Right atrial pressure $(\mathrm{mm} \mathrm{Hg})$ & $3.1(0.3)$ & $3.1(0.5)$ & $3.4(0.3)$ & $3.2(0.2)$ & $3.2(0.1)$ & \\
\hline Cardiac output (I/min) & $6.21(0.48)$ & $7.51(0.37)^{a}$ & $7.35(0.52)^{\mathrm{a}}$ & $7.09(0.26)^{d}$ & $5.75(0.29)$ & $p=0.02$ \\
\hline Heart rate $\left(\min ^{-1}\right)$ & $76(4)$ & $72(2)$ & $81(4)$ & $75(2)$ & $73(2)$ & \\
\hline Stroke volume (ml) & $82(5)$ & $108(6)^{a b}$ & $93(8)$ & $96(4)^{a}$ & $80(5)$ & $\mathrm{p}<0.01$ \\
\hline \multicolumn{7}{|l|}{ Systemic vascular resistance } \\
\hline$\left(\right.$ dyn $\left.\mathrm{s} / \mathrm{cm}^{5}\right)$ & $1272(83)$ & $1031(72)^{a}$ & $973(84)^{a b}$ & $1082(48)^{d}$ & $1398(98)$ & $\mathrm{p}<0.005$ \\
\hline Plasma volume $(\mathrm{ml} / \mathrm{kg})$ & $51.9(2.7)$ & $57.3(2.7)$ & $55.2(2.9)$ & $55.2(1.6)^{a}$ & $47.0(3.3)$ & $\mathrm{p}<0.05$ \\
\hline Blood volume $(\mathrm{ml} / \mathrm{kg})$ & $82.4(3.6)$ & $87.9(3.9)$ & $82.5(4.4)$ & $84.9(2.3)^{\mathrm{a}}$ & $75.1(5.4)$ & $p<0.05$ \\
\hline Central blood volume (ml/kg) & $23.4(1.7)$ & $22.9(1.0)$ & $20.6(1.4)$ & $22.5(0.8)$ & $23.7(2.6)$ & \\
\hline Central circulation time (s) & $14.7(0.6)$ & $13.5(0.5)^{c}$ & $11.3(0.5)^{a b}$ & $12.5(0.4)^{\mathrm{a}}$ & $14.3(1.1)$ & $\mathrm{p}<0.001$ \\
\hline Arterial $\mathrm{O}_{2}$ saturation (\%) & $95(0.6)$ & $95(1.1)$ & $96(0.7)$ & $95(0.6)$ & $95(1.1)$ & \\
\hline Arterial $\mathrm{pO}_{2}(\mathrm{kPa})$ & $10.9(0.4)$ & $11.1(0.5)$ & $10.3(0.7)$ & & $11.2(0.6)$ & \\
\hline Arterial $\mathrm{pCO}_{2}(\mathrm{kPa})$ & $4.9(0.1)$ & $4.4(0.1)^{a b}$ & $4.1(0.2)^{a b}$ & $4.5(0.1)^{d}$ & $5.3(0.1)$ & $p<0.001$ \\
\hline Arterial $\mathrm{pH}$ & $7.41(0.01)$ & $7.43(0.01)$ & $7.45(0.01)^{a b}$ & $7.43(0.005)$ & $7.41(0.005)$ & $\mathrm{p}<0.01$ \\
\hline QT (s) & $0.381(0.010)$ & $0.411(0.011)$ & $0.389(0.014)$ & $0.397(0.007)$ & $0.397(0.006)$ & \\
\hline $\mathrm{QT}_{\mathrm{c}}\left(\mathrm{s}^{1 / 2}\right)$ & $0.428(0.009)$ & $0.445(0.010)$ & $0.447(0.012)^{a}$ & $0.440(0.006)$ & $0.420(0.006)$ & $\mathrm{p}<0.05$ \\
\hline $\mathrm{QT}_{\mathrm{c}}>0.440 / \mathrm{QT}_{\mathrm{c}} \leqslant 0.440$ & $3 / 11(n=14)$ & $10 / 13$ & $7 / 3(n=10)$ & $20 / 27(n=47)$ & $1 / 12$ & \\
\hline
\end{tabular}

Values are mean (SEM).

Significant difference $(p<0.05)$ from: ${ }^{a}$ controls, ${ }^{b}$ Child class $A$, and ${ }^{c}$ Child class $C$; and $(p<0.01)$ from ${ }^{d}$ controls. 


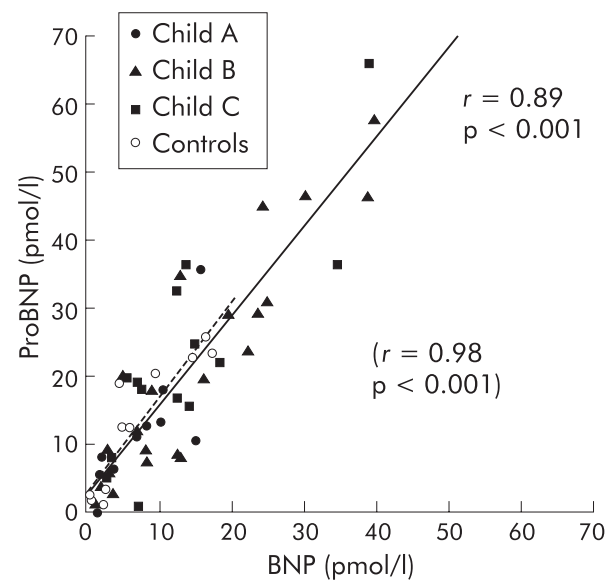

Figure 1 Relation between arterial concentrations of pro-brain natriuretic peptide (proBNP) and brain natriuretic peptide (BNP) in control subjects and patients with cirrhosis. (Controls, broken line, $r=0.98, p<0.001$; patients with cirrhosis, solid line, $r=0.89$, $\mathrm{p}<0.001)$.

$(r=0.34, \mathrm{p}=0.02)$. A borderline significant direct relation was found between BNP and central blood volume $(r=0.26$, $\mathrm{p}=0.07)$. Plasma proBNP and BNP were both inversely related to arterial carbon dioxide tension $(r=-0.42$ and $r=-0.28, \mathrm{p}=0.05)$.

In univariate analyses, no significant relations were found between circulating proBNP and BNP concentrations on the one hand and right atrial pressure, cardiac output, arterial blood pressure, systemic vascular resistance, or heart rate on the other.

In the multiple regression analysis, circulating proBNP concentration was significantly related to mean arterial blood pressure, Child score, body mass index, arterial carbon dioxide and oxygen tensions, heart rate, and QT interval, and borderline significantly to $\mathrm{QT}_{\mathrm{c}}(\mathrm{p}=0.1)$, as shown in table 6. Likewise, circulating BNP concentration was independently related to Child score, arterial oxygen tension,
Table 5 Hepatic disposal of pro-brain natriuretic peptide (proBNP) and brain natriuretic peptide (BNP) in patients with cirrhosis

\begin{tabular}{|c|c|c|}
\hline & Cirrhosis $(n=51)$ & Controls ( $n=13$ ) \\
\hline \multicolumn{3}{|l|}{ ProBNP } \\
\hline Hepatic vein (pmol/l) & $17.7(2.0)$ & $12,4(5.0)(n=5)$ \\
\hline (Artery, pmol/l) $\dagger$ & $(18.3)(2.1) \dagger$ & $(14.6)(5.9) \dagger$ \\
\hline Extraction ratio & $0.05(0.038)$ & $0.09(0.036)(n=5)$ \\
\hline Clearance (ml/min) & $23(45)$ & $22(25)$ \\
\hline Disposal rate (pmol/min) & $0.73(0.48)$ & $0.27(0.17)$ \\
\hline \multicolumn{3}{|l|}{ BNP } \\
\hline Hepatic vein (pmol/l) & $10.1(1.3)$ & $10.1(3.3)(n=8)$ \\
\hline (Artery, pmol/l) $\dagger$ & $(11.8(1.4) \dagger$ & $(12.3(3.4) \dagger$ \\
\hline Extraction ratio & $0.12(0.026)$ & $0.18(0.10)(n=8)$ \\
\hline Clearance (ml/min) & 49 (15) & $68(76)(n=8)$ \\
\hline Disposal rate (pmol/min) & $1.41(0.52)^{a}$ & $0.46(0.13)(n=8)$ \\
\hline \multicolumn{3}{|c|}{$\begin{array}{l}\text { Values are mean (SEM). } \\
\text { +Values in parentheses are corresponding values in the artery obtained } \\
\text { simultaneously with the hepatic vein sample. } \\
\text { aSignificantly different from controls }(p<0.05) \text {. }\end{array}$} \\
\hline
\end{tabular}

heart rate, and QT interval, and borderline significantly to $\mathrm{QT}_{\mathrm{C}}(\mathrm{p}=0.1)$, as shown in table 6 .

Hepatic extraction ratios and disposal rates of plasma proBNP and BNP were not significantly different in cirrhotic patients and controls (table 5).

\section{DISCUSSION}

The present study shows that: firstly, the circulating proBNP concentration is significantly increased in patients with advanced cirrhosis; secondly, circulating proBNP is closely related to BNP; thirdly, no signs of reduced hepatic degradation of proBNP and BNP are present in patients with cirrhosis; and fourthly, elevated proBNP and BNP are related to markers of severity of cirrhosis and cardiac dysfunction, but not to the hyperdynamic circulation.

This is the first study to report increased plasma concentrations of proBNP in patients with cirrhosis. In patients with heart failure, atrial natriuretic peptide (ANP) is known to act as a rapid response hormone and BNP more

Table 4 Arterial and cubital venous pro-brain natriuretic peptide (proBNP) and brain natriuretic peptide (BNP) concentrations in patients with cirrhosis

\begin{tabular}{|c|c|c|c|c|c|}
\hline & \multicolumn{3}{|c|}{ Cirrhosis, Child group (33-69 y) } & \multirow[b]{2}{*}{ Controls $(34-73$ y) $(n=13)$} & \multirow{2}{*}{$\begin{array}{l}\text { Healthy subjects }(23-65 \text { y) } \\
(n=90)\end{array}$} \\
\hline & $A(n=15)$ & $B(n=23)$ & $C(n=13)$ & & \\
\hline \multicolumn{6}{|c|}{ ProBNP (artery) (pmol/l) } \\
\hline Mean & 9.6 & $20.8^{a b}$ & $24.5^{\mathrm{ab}}$ & $13.2^{c}$ & \\
\hline SEM & 2.2 & 3.4 & 4.5 & 2.9 & \\
\hline Median & 9.0 & 18.0 & 20.0 & 12.5 & \\
\hline Range & $(0.0-35.7)$ & $(1.0-57.3)$ & $(1.0-66.0)$ & $(0.71-26)$ & \\
\hline \multicolumn{6}{|c|}{ ProBNP (cubital vein) (pmol/l) } \\
\hline Mean & $10.0^{*}$ & $20.7^{* a}$ & $23.9 * a$ & $14.2^{* c}$ & 2.2 \\
\hline SEM & 1.7 & 4.8 & 5.7 & 2.6 & 0.4 \\
\hline Median & 10.0 & 17.0 & 19.0 & 13.5 & \\
\hline Range & $(0.0-22)$ & $(20-62)$ & $(1.0-58)$ & $(1.0-27)$ & $(0-16)$ \\
\hline \multicolumn{6}{|c|}{ BNP (artery) (pmol/l) } \\
\hline Mean & 5.9 & $14.3^{a b}$ & $14.3^{a b}$ & $7.9^{c}$ & \\
\hline SEM & 1.3 & 2.4 & 3.0 & 1.7 & \\
\hline Median & 5.3 & 12.4 & 12.1 & 5.8 & \\
\hline Range & $(0.8-15.2)$ & $(1.3-39.3)$ & $(3.1-38.5)$ & $(0.5-16.9)$ & \\
\hline \multicolumn{6}{|c|}{ BNP (cubital vein) (pmol/l) } \\
\hline Mean & 5.9 & $13.6^{* a b}$ & $14.7^{* a b}$ & $4.7^{c}$ & 1.7 \\
\hline SEM & 1.2 & 2.2 & 3.5 & 1.5 & 0.1 \\
\hline Median & 5.3 & 14.4 & 13.3 & 4.9 & \\
\hline Range & $(1.4-14.4)$ & $(2.0-29.9)$ & $(2.3-41.9)$ & $(0.6-13.9)$ & $(0-5.3)$ \\
\hline \multirow{2}{*}{\multicolumn{6}{|c|}{ Ratio }} \\
\hline \multicolumn{4}{|c|}{ ProBNP/BNP } & & \\
\hline Mean & 1.81 & 1.60 & 1.97 & 2.28 & \\
\hline SEM & 0.24 & 0.18 & 0.28 & 0.39 & \\
\hline
\end{tabular}

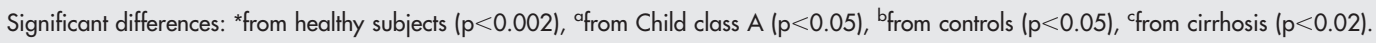



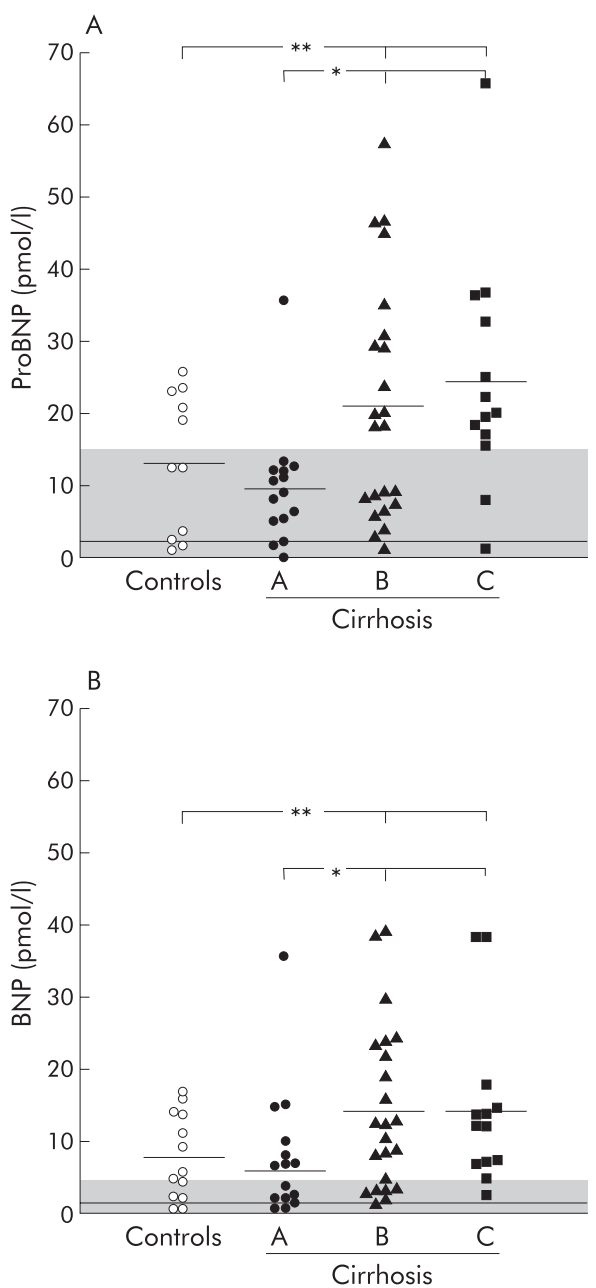

Figure 2 (A) Pro-brain natriuretic peptide (proBNP) concentrations in control subjects and patients with cirrhosis according to Child class. (B) Arterial brain natriuretic peptide (BNP) concentrations in controls and patients with cirrhosis according to Child class. Shaded area is the reference interval; solid lines are mean values. ${ }^{*} \mathrm{p}<0.05,{ }^{* *} \mathrm{p}<0.02$.

as a "back up hormone" activated only after prolonged ventricular overload. ${ }^{30}{ }^{34-36}$ The biological effects of ANP and BNP are natriuresis, diuresis, and vascular relaxation, but patients with cirrhosis, especially with advanced disease, may be resistant to these effects. ${ }^{19}{ }^{37}$ The BNP gene is predominantly expressed in myocytes of failing left ventricles, with BNP increasingly secreted into the circulation. Thus increased plasma concentrations of BNP are associated with impaired function of the left ventricle regardless of the underlying course. The larger $\mathrm{N}$ terminal prohormone fragments of proBNP are more stable and have been suggested to have a longer biological half life. Finally, the requirements for blood sampling are less critical. Circulating proBNP concentration is less sensitive to rapid fluctuations caused by short term stimuli of secretion, such as change in body posture, exercise, or volume changes. ProBNP has therefore been suggested as an even better marker of heart failure than BNP. ${ }^{21-24} \mathrm{~A}$ few previous studies have reported increased plasma BNP concentrations in patients with cirrhosis. ${ }^{15-20}$

The natriuretic peptides are synthesised as pre-prohormones with endocrinologically active $C$ terminal peptides. ${ }^{34}$ It is uncertain at present whether proteolytic clevage of proBNP to $\mathrm{N}$ terminal proBNP $1-76$ and BNP occurs at the time of secretion or later in the circulation, although recent investigations suggest that proBNP is split mainly within or at the surface of the cardiomyocytes. ${ }^{38}$ The half life of the
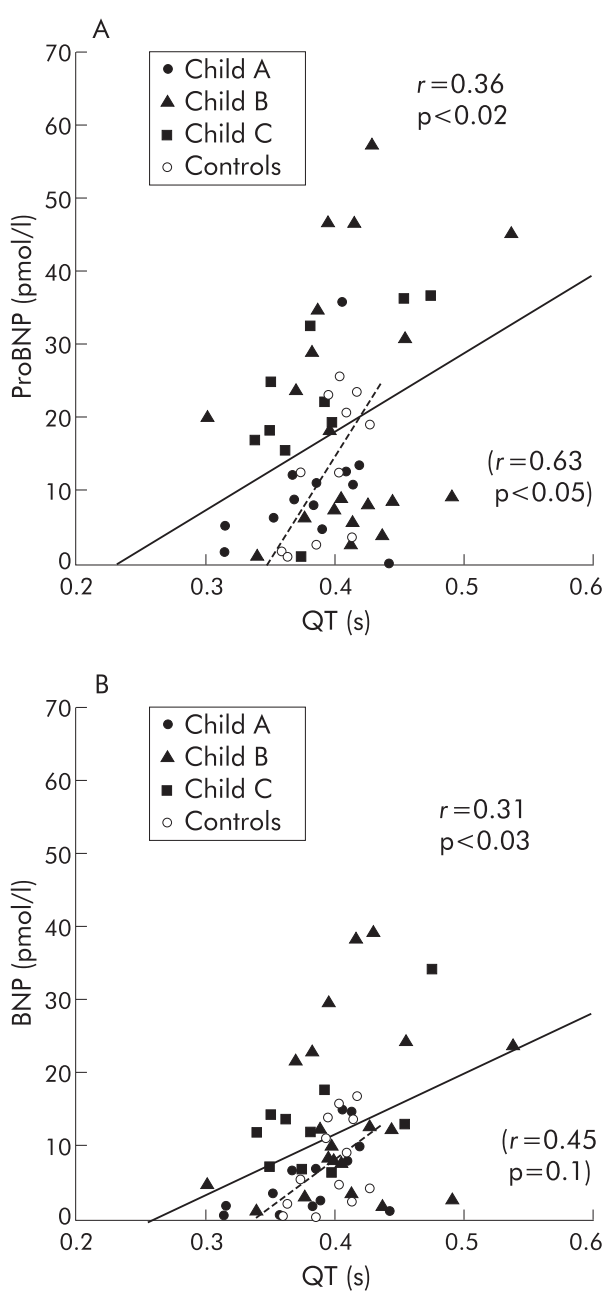

Figure 3 Circulating pro-brain natriuretic peptide (proBNP) (A) and brain natriuretic peptide (BNP) (B) concentrations in relation to $Q T$ interval. Solid line, cirrhosis; broken line, controls.

prohormones and stability in plasma may provide a better profile for detecting increased myocyte release than the biologically active hormones. ${ }^{39}$ Therefore, attention has turned to determination of circulating levels of pro-ANP and proBNP as indices of atrial and ventricular strain, respectively. However, there may be problems, especially in patients with cirrhosis, with clevage of proBNP to smaller fragments, interference with plasma proteins, and changed hepatic degradation. In the present study, we used an assay for proBNP that involved clevage with trypsin and antibodies directed towards epitopes specific in the $\mathrm{N}$ terminal 1-21 propeptide. ${ }^{30}$ It has previously been validated that this assay measures intact proBNP and $\mathrm{N}$ terminal proBNP fragments with equimolar potency, thus determining the total concentration of proBNP in plasma. ${ }^{30}$ Any non-specific interference of larger proteins in plasma was eradicated by treating the samples with trypsin. Earlier control experiments have shown that when left at room temperature for 24 hours, the present assay did not reveal any significant decrease in endogenous $\mathrm{N}$ terminal proBNP immunoreactivity. Finally, hepatic venous-arterial extraction and disposal rate of both proBNP and BNP were not significantly different in cirrhotic and normal livers, a finding in accordance with earlier investigations on ANP. ${ }^{40}$ This suggests that the increased circulating levels of proBNP and BNP in patients with cirrhosis in the main reflect increased secretion from the heart rather than a reduced hepatic disposal. 
Table 6 Relations between arterial pro-brain natriuretic peptide (proBNP) and brain natriuretic peptide (BNP) concentrations and clinical, cardiac, and haemodynamic variables in multiple regression analysis

\begin{tabular}{|c|c|c|c|}
\hline Variable & Regression coefficient & SEM & $\mathrm{p}$ Value \\
\hline \multicolumn{4}{|c|}{ Arterial proBNP versus variables (cirrhosis, $n=51$ ) } \\
\hline Mean arterial pressure $(\mathrm{mm} \mathrm{Hg})$ & -0.506 & 0.118 & $<0.0001$ \\
\hline Child score & 4.703 & 1.214 & 0.0004 \\
\hline Arterial $\mathrm{CO}_{2}$ tension $(\mathrm{kPa})$ & -10.73 & 3.11 & 0.001 \\
\hline RR interval (s) & -0.449 & 0.140 & 0.003 \\
\hline Body mass index $\left(\mathrm{kg} / \mathrm{m}^{2}\right)$ & -12.84 & 4.12 & 0.003 \\
\hline Arterial $\mathrm{O}_{2}$ tension $(\mathrm{kPa})$ & -2.570 & 0.911 & 0.007 \\
\hline QT (s) & 7.77 & 3.18 & 0.019 \\
\hline $\mathrm{QT}_{\mathrm{c}}\left(\mathrm{s}^{1 / 2}\right)$ & & & 0.1 \\
\hline$\left(r^{2}\right.$ for model $\left.=0.569, p=0.000006\right)$ & 80.16 & & \\
\hline \multicolumn{4}{|c|}{ Arterial BNP versus variables (cirrhosis, $n=51$ ) } \\
\hline RR interval (s) & -0.371 & 0.102 & 0.0008 \\
\hline Arterial $\mathrm{O}_{2}$ tension $(\mathrm{kPa})$ & -1.865 & 0.650 & 0.006 \\
\hline Child score & 2.270 & 0.813 & 0.008 \\
\hline QT (s) & 6.254 & 2.42 & 0.013 \\
\hline $\mathrm{QT}_{\mathrm{c}}\left(\mathrm{s}^{1 / 2}\right)$ & & & 0.1 \\
\hline$\left(r^{2}\right.$ for model $\left.=0.394, p=0.0001\right)$ & 41.11 & & \\
\hline
\end{tabular}

A significant difference was established between average proBNP and BNP concentrations of class A and class $\mathrm{C}$ patients, and a significant correlation was observed with Child score, coagulation factors 2, 7, and 10, and albumin level, indicating a relation with severity of liver disease. This is in keeping with earlier observations that cardiac dysfunction is more frequent and pronounced in patients with severe than mild liver disease. ${ }^{8}{ }^{12}$ These findings were confirmed by multiple regression analysis that, in addition to relation to severity of liver disease and markers of cardiac dysfunction, also suggested a possible relation to low arterial oxygen tension and hyperventilation, which are markers of advanced liver disease.

Circulating proBNP and BNP concentrations may increase with age..$^{30}$ The increase is weak in subjects less than 70 years of age, but in elderly subjects above this age circulating concentrations of proBNP increase substantially. This may in part reflect unmasked heart failure, but in elderly healthy individuals with a normal exercise test, echocardiography, etc., circulating values of proBNP seem higher than in younger subjects. ${ }^{30}$ Therefore, age matched controls are important. Patients with cirrhosis had significantly higher values than age matched controls, who in turn had higher values than age matched healthy subjects. This may suggest the presence of latent heart failure in both cirrhotic patients and control subjects without liver disease. It should be noted that in both groups of subjects, a close direct correlation between proBNP and BNP concentrations was present. The proBNP/BNP ratio was somewhat lower in cirrhotic patients compared with controls, but this value did not achieve statistical significance. Highly different ratios between proBNP and BNP have been reported previously with different assays, which most likely reflects different specificity and sensitivity of the assays. ${ }^{30}$ The present results confirmed that levels of circulating proBNP and BNP were of the same picomolar order, although concentrations of proBNP were significantly higher than those of BNP, reflecting their different stability, which was also confirmed in patients with cirrhosis.

In the present study, no significant relationship was established between proBNP and BNP on the one hand and indicators of hyperdynamic circulation (such as cardiac output, systemic vascular resistance) on the other. A direct relation was found between plasma concentrations of these peptides and QT interval. This finding may therefore suggest that increased circulating proBNP and BNP concentrations are not merely a consequence of the hyperdynamic circulation but rather related to cardiac dysfunction, which in turn is more prominent in severe disease. The fact that the relation between proBNP and BNP on the one hand and $\mathrm{QT}_{\mathrm{C}}$ on the other hand did not achieve statistical significance may reflect different effects of prolonged QT and heart rate.

Cirrhotic patients had no signs of central overfilling, as central blood volume was either normal or reduced. Thus increased concentrations of proBNP and BNP were not caused by central volume overloading. However, even patients with a decreased central blood volume may have locally expanded subcompartments such as the left ventricle. In an earlier study of patients with cirrhosis, we found a direct relation between end diastolic ventricular volume and central blood volume. ${ }^{41}$ In the present study, a borderline significant relation was found between plasma concentrations of BNP and central blood volume, and this reached statistical significance with respect to plasma volume. Abnormal distribution of the circulating medium may thus contribute to demask overt cardiac failure in patients with cirrhosis. $^{7} 1012$

The experimental data advocating the existence of cirrhotic cardiomyopathy derive from research in chronic bile duct ligated rats. ${ }^{13} 42-44$ Moreover, animals with portal vein ligation display abnormalities in the coupling between excitation and contraction of the myocytes, ${ }^{45}$ and a recent report on patients with extrahepatic portal hypertension has shown prolonged QT interval comparable with that found in patients with cirrhosis. ${ }^{46}$ Thus portal hypertension with or without liver dysfunction may lead to cardiac dysfunction. In the present study, all patients had alcoholic cirrhosis. Alcohol is well known to be toxic to myocytes, ${ }^{12}{ }^{47}$ and on the present data it cannot be established to which degree cardiac dysfunction is due to sequelae after alcohol ingestion or to the combined effect of portal hypertension and liver disease.

In conclusion, accurate quantification of plasma proBNP and its products, irrespective of the degree of prohormone processing, has revealed increased concentrations of circulating proBNP in patients with advanced cirrhosis. Unchanged hepatic degradation of proBNP and a relation between plasma proBNP concentration and severity of disease and markers of heart dysfunction, but not markers of hyperdynamic circulation, suggest that elevated concentrations of proBNP may indicate the presence of cardiac dysfunction in advanced alcoholic cirrhosis. 


\section{ACKNOWLEDGEMENTS}

The authors wish to express their gratitude to the technicians and nurses of the Department of Clinical Physiology for helpful assistance. The study was supported by a grant from the John and Birthe Meyer Foundation and by the Klein Prize. The authors are grateful to Hanne B Hansen, MSc, Bente Henriksen, Lone Olsen, and Rosemary Sørensen for skilful assistance.

\section{Authors' affiliations}

J H Henriksen, S Fuglsang, S Møller, Department of Clinical Physiology, 239, Hvidovre Hospital, Hvidovre, Denmark

J P Gøtze, Department of Clinical Biochemistry, Rigshospitalet, Copenhagen, Denmark

E Christensen, Department of Medicine I, Bispebjerg Hospital, Unversity of Copenhagen, Copenhagen, Denmark

F Bendtsen, Department of Gastroenterology, 439, Hvidovre Hospital, Hvidovre, Denmark

\section{REFERENCES}

1 Schrier RW, Arroyo V, Bernardi M, et al. Peripheral artery vasodilatation hypotheses: a proposal for the initiation of renal sodium and water retention in cirrhosis. Hepatology 1988:8:1151-7.

2 Møller S, Henriksen JH. Circulatory abnormalities in cirrhosis with focus on neurohumoral aspects. Semin Nephrol 1997;17:505-19.

3 Naschitz JE, Slobodin G, Lewis RJ, et al. Heart diseases affecting the liver and liver diseases affecting the heart. Am Heart J 2000;140:111-20.

4 Estruch R, Fernandezsola J, Sacanella E, et al. Relationship between cardiomyopathy and liver disease in chronic alcoholism. Hepatology 1995;22:532-8.

5 Pozzi M, Carugo S, Boari G, et al. Evidence of functional and structural cardiac abnormalities in cirrhotic patients with and without ascites. Hepatology 1997;26:1131-7.

6 Laffi G, Barletta G, La Villa G, et al. Altered cardiovascular responsiveness to active tilting in nonalcoholic cirrhosis. Gastroenterology 1997;113:891-8.

7 Valeriano V, Funaro S, Lionetti R, et al. Modification of cardiac function in cirrhotic patients with and without ascites. Am J Gastroenterol 2000:95:3200-5.

8 Bernardi M, Calandra S, Colantoni A, et al. QT interval prolongation in cirrhosis: Prevalence, relationship with severity, and etiology of the disease and possible pathogenetic factors. Hepatology 1998;27:28-34.

9 Henriksen JH, Fuglsang S, Bendtsen F, et al. Dyssynchronous electrical and mechanical systole in patients with cirrhosis. J Hepatol 2002:36:513-20.

$10 \mathrm{Ma} \mathrm{Z}$, Lee S. Cirrhotic cardiomyopathy: getting to the heart of the matter Hepatology 1996;24:451-9.

$11 \mathrm{Ma} \mathrm{Z}$, Miyamoto A, Lee SS. Role of altered beta-adrenoceptor signa transduction in the pathogenesis of cirrhotic cardiomyopathy in rats. Gastroenterology 1996;110:1191-8.

12 Møller S, Henriksen JH. Cirrhotic cardiomyopathy: a pathophysiological review of circulatory dysfunction in liver disease. Heart 2002;87 9-15.

13 Liu H, Ma Z, Lee SS. Contribution of nitric oxide to the pathogenesis of cirrhotic cardiomyopathy in bile duct-ligated rats. Gastroenterology 2000; 118:937-44.

14 Pateron D, Beyne P, Laperche T, et al. Elevated circulating cardiac troponin I in patients with cirrhosis. Hepatology 1999;29:640-3.

15 LaVilla G, Romanelli RG, Casini Raggi V, et al. Plasma levels of brain natriuretic peptide in patients with cirrhosis. Hepatology 1992;16:156-61.

16 Wong F, Siu S, Liu P, et al. Brain natriuretic peptide: is it a predictor of cardiomyopathy in cirrhosis? Clin Sci 2001;101:621-8.

17 Iwau T, Oho K, Nakano R, et al. High plasma cardiac natriuretic peptides associated with enhanced cyclic guanosine monophosphate production in preascitic cirrhosis. J Hepatol 2000;32:426-33.

18 Komeichi H, Moreau R, Cailmail S, et al. Blunted natriuresis and abnormal systemic haemodynamic responses to $\mathrm{C}$-type and brain natriuretic peptides in rats with cirrhosis. J Hepatol 1995:22:319-25.

19 La Villa G, Riccardi D, Lazzeri C, et al. Blunted natriuretic response to lowdose brain natriuretic peptide infusion in nonazotemic cirrhotic patients with ascites and avid sodium retention. Hepatology 1995;22:1745-50.

20 Salo J, Jimenez W, Kuhn M et al. Urinary excretion of urodilatin in patients with cirrhosis. Hepatology 1996;24:1428-32.

21 Hunt PJ, Richards AM, Nicholls MG, et al. Immunoreactive amino-terminal pro-brain natriuretic peptide (NT-proBNP): a new marker of cardiac impairment. Clin Endocrinol 1997:47:287-96.
22 Hughes D, Talwar S, Squire IB, et al. An immunoluminometric assay for Nterminal pro-brain natriuretic peptide: development of a test for left ventricular dysfunction. Clin Sci 1999;96:373-80.

23 Campell DJ, Mitchelhill KI, Schlicht SM, et al. Plasma aminoterminal pro-brain natriuretic peptide: a novel approach to the diagnosis of cardiac dysfunction. J Card Fail 2000;6:130-9.

24 Goetze JP, Kastrup J. Plasma pro-brain natriuretic peptides are strong biochemical markers in clinical cardiology. Scand J Clin Lab Invest $2001 ; 61$ (suppl 234):47-51

25 Henriksen JH, Bendtsen F, Sørensen TIA, et al. Reduced central blood volume in cirrhosis. Gastroenterology 1989;97:1506-13.

26 Møller S, Wiinberg N, Henriksen JH. Noninvasive 24-hour ambulatory arterial blood pressure monitoring in cirrhosis. Hepatology 1995;22:88-95.

27 Henriksen JH, Fuglsang S, Bendtsen F, et al. Arterial compliance in patients with cirrhosis. Am J Physiol Gastrointest 2001;280:G584-94.

28 Henriksen JH, Winkler K. Hepatic blood flow determination - a comparison of ${ }^{99 m}$ Tc-diethyl-IDA and indocyanine green as hepatic blood flow indicators in man. J Hepatol 1987;4:66-70.

29 Christensen PK, Gall M-A, Major-Pedersen A, et al. QTc interval length and QT dispersion as predictors of mortality in patients with non-insulin-dependent diabetes. Scand J Clin Lab Invest 2000;60:323-32.

30 Goetze JP, Kastrup J, Pedersen F, et al. Quantification of pro-B-type natriuretic peptide and its products in human plasma by use of an analysis independent of precursor processing. Clin Chem 2002;48:1035-42.

31 Redfield MM, Rodeheffer RJ, Jacobsen SJ, et al. Plasma brain natriuretic peptide concentration: impact of age and gender. J Am Coll Cardiol 2002:40:976-82

32 Nishikimi T, Yoshihara F, Morimoto A, et al. Relationship between leff ventricular geometry and natriuretic peptide levels in essential hypertension. Hypertension 1996;28:22-30.

33 Clerico A, Del Ry S, Maffei S, et al. The circulating levels of cardiac natriuretic hormones in healthy adults: effects of age and sex. Clin Chem Lab Med 2002;40:371-7.

34 Boomsma F, van den Meiracker AH. Plasma A- and B-type natriuretic peptides: physiology, methodology and clinical use. Cardiovasc Res 2001;51:442-9.

35 Levin ER, Gardner DG, Samson WK. Natriuretic peptides. N Engl J Med 1998;339:321-8

36 Luchner A, Stevens TL, Borgeson DD, et al. Differential atrial and ventricular expression of myocardial BNP during the evolution of heart failure. Am J Physiol 1998;274:H1684-9.

37 Laffi G, Pinzani M, Meacci $E$, et al. Renal haemodynamic and natriuretic effects of human atrial natriuretic factor infusion in cirrhosis with ascites. Gastroenterology 1989;96:167-7

38 Yan W, Wu F, Morser J, et al. Corin, a transmembrane cardiac serine protease, acts as a pro-atrial natriuretic peptide-converting enzyme. Proc Natl Acad Sci U S A 2000:97:8525-9.

39 Yasue $H$, Yoshimura M, Sumida $H$, et al. Localization and mechanism of secretion of B-type natriuretic peptide in camparison with those of A-type natriuretic peptide in normal subjects and in patients with heart failure. Circulation 1994:90:195-203.

40 Bendtsen F, Gerbes AL, Henriksen JH. Disposal of atrial natriuretic factor (ANF99-126) in patients with cirrhosis: effect of beta-adrenergic blockade. Scand J Clin Lab Invest 1993:53:547-54.

41 Møller S, Søndergaard L, Møgelvang J, et al. Decreased right heart blood volume determined by magnetic resonance imaging: evidence of central underfilling in cirrhosis. Hepatology 1995;22:472-8.

42 Bomzon A. The effect of bile duct manipulation on cardiovascular responsiveness: in vivo studies. J Pharmacol Toxicol Methods 1998;39: 75-9.

43 Gazawi H, Ljubuncic P, Cogan U, et al. The effects of bile acids on beta-adrenoceptors, fluidity, and the extent of lipid peroxidation in rat cardiac membranes. Biochem Pharmacol 2000:59: 1623-8.

44 van Obbergh L, Vallieres $Y$, Blaise $G$. Cardiac modifications occurring in the ascitic rat with biliary cirrhosis are nitric oxide related. J Hepatol 1996:24:747-52.

45 Zavecz JH, Bueno O, Maloney RE, et al. Cardiac excitation-contraction coupling in the portal hypertensive rat. Am J Physiol Gastrointest Liver Physiol 2000;279:G28-39.

46 Trevisani F, Merli M, Savelli F, et al. QT interval in patients with non-cirrhotic portal hypertension and in cirrhotic patients treated with transjugular intrahepatic portosystemic shunt. J Hepatol 2003;38:461-7.

47 Harcombe AA, Ramsay L, Kenna JG et al. Circulating antibodies to cardiac protein-acetaldehyde adducts in alcoholic heart muscle disease. Clin Sci $1995 ; 88: 263-8$ 